\title{
Velocidade de infiltração básica de água como indicador da qualidade porosa do solo
}

Myashiro Fortes de Souza ${ }^{1}$

Raphael Maia Aveiro Cessa ${ }^{2}$

Elizeu Luiz Brachtvogel ${ }^{3}$

Fábio Régis de Souza ${ }^{4}$

Elói Panachuki ${ }^{5}$

Igor Junior Hoppen Varão

Jeyssa Santino Costa ${ }^{7}$

Markondes Lacerda Araújo ${ }^{8}$

Patrícia Simone Kranz Caçol ${ }^{9}$

\section{Resumo}

Objetivou-se com este trabalho analisar se a velocidade de infiltração básica de água (VIB) pode ser um indicador da qualidade do sistema poroso do solo cultivado com diferentes espécies vegetais. Foi realizado no Município de Confresa (MT) em um Argissolo Vermelho Amarelo de textura arenosa. O delineamento experimental foi o de blocos casualizados com quatro tratamentos constituídos pelos cultivos de Brachiaria ruziziensis (braquiária), Pennisetum americanum (milheto), Phaseolus vulgaris L. (feijão) e Sorghum bicolor L. Moench (sorgo) em quatro repetições totalizando 16 parcelas, com posterior cultivo de milho. A ideia do cultivo das referidas espécies vegetais foi promover alteração natural do calibre dos poros do solo por meio dos seus sistemas radiculares e mineralização dos resíduos, viabilizando o estudo da velocidade de infiltração básica de água no solo como indicador da qualidade do calibre de poros. A partir de 90 dias após semeadura do milho avaliou-se a densidade do solo, volume de macroporos (Ma), microporos (Mi), porosidade total (VTP), resistência do solo à penetração (Rsp) e VIB. As profundidades do solo consideradas foram 0,00 a 0,10 m e 0,10 a 0,20 m. Os dados numéricos foram submetidos a análise de variância e teste de significância de "F" ao nível de 5\% de probabilidade. Características significativas tiveram suas médias comparadas pelo método Tukey. Entre as características citadas obtiveram-se os coeficientes de correlação lineares simples de Pearson. Nas condições experimentais avaliadas foi possível utilizar a

${ }^{1}$ Instituto Federal de Educação, Ciência e Tecnologia do Mato Grosso - Campus Confresa, Acadêmico do Ensino Superior — Técnico em Agropecuária. Confresa, MT, Brasil.mshiro@hotmail.com. (066) 3464-2600. Avenida Vilma Fernandes, 300, Setor Santa Luzia, Confresa, MT, CEP 78652-000.

2Instituto Federal de Educação, Ciência e Tecnologia de Mato Grosso - Campus Confresa, Professor do Ensino Básico, Técnico e Tecnológico - Área Agronomia. Confresa, MT, Brasil. rapha-el.cessa@cfs.ifmt.edu.br. (066) 3464-2600. Avenida Vilma Fernandes, 300, Setor Santa Luzia, Confresa, MT, CEP 78652-000.

${ }^{3}$ Instituto Federal de Educação, Ciência e Tecnologia de Mato Grosso - Campus Confresa, Professor do Ensino Básico, Técnico e Tecnológico - Área Agronomia. Confresa, MT, Brasil. eli-zeu.brachtvogel@cfs.ifmt.edu.br. (066) 3464-2600. Avenida Vilma Fernandes, 300, Setor Santa Luzia, Confresa, MT, CEP 78652-000.

${ }^{4}$ Centro Universitário da Grande Dourados, Professor do Ensino Superior - Área Agronomia. Dourados, Mato Grosso do Sul, Brasil. fabio. souza@unigran.com.br. (067) 3411-4141. Rua Balbina de Matos, 2121, Jardim Universitário, Dourados, MS, CEP 79824-900.

${ }^{5}$ Universidade Estadual de Mato Grosso do Sul - Campus Aquidauana, Professor do Magistério Superior - Área Agronomia. Aquidauana, Mato Grosso do Sul, Brasil. eloip@uems.com.br. (067) 3904-2907. Rodovia Aquidauana, km 12, Setor Santa Luzia, Aquidauana, MS, CEP 79200-000.

${ }^{6}$ Instituto Federal de Educação, Ciência e Tecnologia do Mato Grosso - Campus Confresa, Acadêmico do Ensino Médio - Técnico em Agropecuária. Confresa, MT, Brasil. igorjuniorhoppen@gmail.com. (066) 3464-2600. Avenida Vilma Fernandes, 300, Setor Santa Luzia, Confresa, MT, CEP 78652-000.

${ }^{7}$ Instituto Federal de Educação, Ciência e Tecnologia do Mato Grosso - Campus Confresa, Acadêmica do Ensino Médio - Técnico em Agropecuária. Confresa, MT, Brasil. tecnica.agrop.ifmt@hotmail.com. (066) 3464-2600. Avenida Vilma Fernandes, 300, Setor Santa Luzia, Confresa, MT, CEP 78652-000.

${ }^{8}$ Instituto Federal de Educação, Ciência e Tecnologia do Mato Grosso - Campus Confresa, Acadêmico do Ensino Médio - Técnico em Agropecuária. Confresa, MT, Brasil. markondearaujo@gmail.com. (066) 3464-2600. Avenida Vilma Fernandes, 300, Setor Santa Luzia, Confresa, MT, CEP 78652-000.

${ }^{9}$ Instituto Federal de Educação, Ciência e Tecnologia do Mato Grosso - Campus Confresa, Acadêmica do Ensino Médio - Técnico em Agropecuária. Confresa, MT, Brasil. patyfofak@hotmail.com. (066) 3464-2600. Avenida Vilma Fernandes, 300, Setor Santa Luzia, Confresa, MT, CEP 78652-000. 
VIB como indicador da qualidade do seu sistema poroso, embora tenha sido necessário realizar associações indiretas com as características avaliadas. Dessa forma, constatou-se tendência do aumento da VIB com aumento da macroporosidade.

Palavras chave: Porosidade. Manejo. Resíduos vegetais.

\section{Introdução}

O conhecimento do processo de infiltração de água no solo e sua relação com as características do solo - principalmente físicas - são de fundamental significância para o eficiente manejo do solo e da água (SOBRINHO et al., 2003). Inicialmente, a infiltração da água no perfil do solo é elevada, diminuindo com o tempo, até se tornar constante no momento em que o solo tornar-se saturado (BRANDÃO et al., 2009).

A taxa de infiltração de água no solo é controlada pelos poros de maior calibre sem influência da força capilar e pela rugosidade de superfície, determinantes ao balanço de água na zona das raízes e o deflúvio superficial (CABEDA, 1984). Possivelmente é a propriedade físico-hídrica que melhor "reflete" ou atua como indicador qualitativo básico das condições físicas gerais do solo (ALVES; CABEDA, 1999; DORAN; PARKIN, 1994). Nesse sentido, a taxa de infiltração pode sugerir estados de degradação do sistema poroso dos solos.

A redução do espaço poroso da camada agricultável de um solo, por ocasião da sua desestruturação permitida em técnicas inadequadas de manejo, reduz a infiltração de água, desfavorecendo o melhoramento dos seus aspectos físicos e químicos. A porosidade do solo está relacionada a sua estruturação, que por sua vez é influenciada pela sua composição volumétrica, ocasionando diretamente ou indiretamente alterações sobre a infiltração, permeabilidade e retenção da água no solo (KIEHL, 1979). Assim, é possível alterar as propriedades físico-hídricas dos solos conforme o sistema de manejo praticado (BARCELOS et al., 1999).

A destruição dos agregados do solo pela energia cinética das gotas de chuva e/ou pelo seu preparo mecânico intenso, por exemplo, ocasiona alteração da sua estrutura, culminando no "selamento" das camadas mais superficiais, redução da porosidade total e, principalmente, da macroporosidade, diminuindo a taxa de infiltração de água no solo (PANACHUKI et al., 2006)

Nos sistemas agrícolas conservacionistas, a mitigação da desestruturação dos agregados do solo dá-se pelo cultivo sucessor ou rotativo das espécies vegetais. Daí a importância de se conhecer aspectos da decomposição dos resíduos de várias espécies vegetais na superfície do solo; pode ser rápida e intensa (ROSOLEM et al., 2003), ou lenta e gradual, conforme a interação entre os fatores climáticos, principalmente precipitação pluvial e temperatura, atividade macro e microbiológica do solo e qualidade e quantidade do resíduo vegetal (ALCÂNTARA et al., 2000; OLIVEIRA et al., 2002).

A permanência dos seus resíduos vegetais em decomposição na superfície do solo, os quais interceptam e dissipam a energia cinética das gotas de chuva (ALVES, 1986; CASSOL, 1986), por ação mecânica de suas raízes e/ou pelo favorecimento da elevação do teor de carbono total no solo (LOVATO et al, 2004) auxiliam na agregação, formação e estabilidade dos agregados do solo (CARPENEDO; MIELNICZUK, 1990; SILVA; KATO, 1998). Com isso, há uma tendência na formação de macroporosidade e porosidade total na camada agricultável (BERTOL et al., 2004; OLIVEIRA et al., 2004).

É importante ressaltar, que o aumento da porosidade total e da macroporosidade dos solos em sistemas de cultivo conservacionistas é favorecido pela atividade relativa de insetos e fungos na formação de bioporos, fato este que também melhora a infiltração de água no solo (DUNN; PHILLIPS, 1991).

Este trabalho objetivou verificar se a velocidade de infiltração básica de água pode ser um indicador da qualidade do sistema poroso do solo cultivado com diferentes espécies vegetais.

\section{Material e Métodos}

O estudo foi realizado no município de Confresa, localizado sob as coordenadas geográficas $10^{\circ} 39^{\prime}$ 40,69" sul e 51 33' 18,24" oeste, e altitude média de 229 m. A classificação climática de Köppen-Geiger do referido município é definida como Aw (tropical com estação seca), com temperatura média de 19 oC e temperaturas médias de mínima e máxima de $19{ }^{\circ} \mathrm{C}$ e $35^{\circ} \mathrm{C}$, respectivamente. 
A precipitação total anual é superior a $1.800 \mathrm{~mm}$.

O solo da área experimental está classificado como Argissolo Vermelho Amarelo (EMBRAPA, 2006) de textura arenosa (22\% de argila na profundidade de 0 a 0,20 m), preparado com uso de grades. Na ocasião, considerando-se as informações da análise química e física do solo para a profundidade de 0,00 a 0,20 m, foram incorporados 1.500 e $350 \mathrm{~kg} / \mathrm{ha}$ de calcário dolomítico e superfosfato simples, respectivamente.

O delineamento experimental foi o de blocos casualizados com quatro tratamentos constituídos pelos cultivos de Brachiaria ruziziensis (braquiária), Pennisetum americanum (milheto), Phaseolus vulgaris L. (feijão) e Sorghum bicolor L. Moench (sorgo) em quatro repetições totalizando 16 parcelas.

A ideia do cultivo das referidas espécies vegetais foi promover alteração natural do calibre dos poros do solo por meio dos seus sistemas radiculares e mineralização dos resíduos, viabilizando o estudo da velocidade de infiltração básica de água no solo como indicador da qualidade do calibre de poros.

As parcelas experimentais tiveram as dimensões de 10,0 m de largura $\times 10,0 \mathrm{~m}$ de comprimento $\left(100 \mathrm{~m}^{2}\right)$. A área útil da parcela foi definida por desconto de uma faixa de $0,50 \mathrm{~m}$ de largura em todas as dimensões (comprimento e largura).

A semeadura (18/12/2012) da braquiária deu-se a lanço, seguida da incorporação das sementes à profundidade média de 0,01 m utilizando-se $35 \mathrm{~kg} / \mathrm{ha}$. Na área de semeadura da braquiária procederam-se três nivelamentos precedentes à sua semeadura. A semeadura de milheto na data de $18 / 12 / 2012$ deu-se em sulcos espaçados a 0,45 m na profundidade média de 0,02 $\mathrm{m}$ utilizando-se $20 \mathrm{~kg} / \mathrm{ha}$. A semeadura (18/12/2012) do feijoeiro deu-se em sulcos espaçados em 0,45 m na profundidade média de 0,03 m permanecendo em média nove plantas por metro linear 20 dias após a semeadura. A semeadura do sorgo, na data de 06/01/2013, deu-se em sulcos espaçados em 0,45 $\mathrm{m}$ na profundidade média de 0,02 m utilizando-se $15 \mathrm{~kg} / \mathrm{ha}$. Aos 25 dias após a semeadura das espécies citadas, procedeu-se a adição a lanço de 50 e $60 \mathrm{~kg} / \mathrm{ha}$ de ureia e cloreto de potássio.

No dia 18 de março de 2013 as espécies vegetais braquiária, milheto, feijoeiro e sorgo foram ceifadas manualmente e, após cinco dias, submetidas a uma pulverização com herbicida para uniformizar o início da senescência. Após a ceifa estimaram-se as perdas das suas biomassas remanescentes na superfície do solo. Para tal, um quadrado de madeira de 0,50 $\mathrm{m}^{2}$ aleatoriamente alocado nas parcelas experimentais serviu para amostragem (coleta da biomassa).

No dia 20 de março de 2013, cultivou-se milho (Zea mays) nas parcelas experimentais no espaçamento de 0,90 m entre linhas de semeadura com seis plantas estabelecidas por metro linear para avaliação da produtividade de grãos de milho na umidade de $14 \%$. A adubação utilizada na semeadura do milho foi $200 \mathrm{~kg} / \mathrm{ha}^{-1}$ do fertilizante mineral formulado $\mathrm{O}(\mathrm{N})-20\left(\mathrm{P}_{2} \mathrm{O}_{5}\right)-20\left(\mathrm{~K}_{2} \mathrm{O}\right)$ e, quando esse encontrava-se com seis pares de folha foi adicionado a lanço $50 \mathrm{~kg} / \mathrm{ha}$ de ureia.

A partir de 90 dias após semeadura do milho avaliou-se a densidade do solo, volume de macroporos e microporos e porosidade total, segundo EMBRAPA (2011) e resistência do solo à penetração com auxílio de penetrógrafo eletrônico introduzido no perfil do solo por meio de um cone com ângulo de $45^{\circ}$ acoplado a uma haste metálica realizando leituras a cada 0,01 m de profundidade. As profundidades do solo consideradas foram 0,00 a $0,10 \mathrm{~m}$ e 0,10 a 0,20 m. A velocidade de infiltração básica foi avaliada pelo método do infiltrômetro de anéis concêntricos (BRANDÃO et. al, 2003).

Os dados numéricos foram submetidos a análise de variância e teste de significância de " $F$ " ao nível de $5 \%$ de probabilidade. Características significativas tiveram suas médias comparadas pelo método Tukey a 5\% de probabilidade (PIMENTEL-GOMES, 1990). Entre as características citadas obtiveram-se os coeficientes de correlação lineares simples de Pearson (BANZATO; KRONKA, 1992).

\section{Resultados e Discussão}

Não foi constatada diferença estatística significativa pelo teste $\mathrm{F}$ da análise de variância do experimento das características densidade do solo (Ds) na profundidade do solo entre 0 e $10 \mathrm{~cm}$ e entre 10 e $20 \mathrm{~cm}$ e volume total de poros (VTP) na profundidade do solo de e 10 a $20 \mathrm{~cm}$ (Tabela $1)$. 
Tabela 1. Valores de quadrado médio do resíduo da análise de variância do experimento para profundidade do solo de 0 a $10 \mathrm{~cm}$ e 10 a $20 \mathrm{~cm}$ das características macroporosidade (Ma), microporosidade (Mi), volume total de poros (VTP), densidade do solo (Ds) e resistência do solo à penetração (Rsp).

\begin{tabular}{ccccccc}
\hline & Ma & Mi & VTP & Ds & Rsp & VIB $^{(1)}$ \\
\hline 0 a $\mathbf{1 0 ~} \mathbf{~ m ~}$ & $69,12^{* *}$ & $70,02^{* *}$ & $47,57^{* *}$ & $0,02 n s$ & $311131,37^{* *}$ & \\
\hline Coef. var. (\%) & $\mathbf{1 7 , 9 8}$ & $\mathbf{6 , 6 3}$ & $\mathbf{5 , 1 1}$ & $\mathbf{6 , 2 7}$ & $\mathbf{4 4 , 7 1}$ & \\
\hline $\mathbf{1 0}$ a $\mathbf{2 0} \mathbf{~ c m}$ & $38,38^{*}$ & $123,74^{\star *}$ & $34,37 n s$ & $0,01 \mathrm{~ns}$ & $\mathbf{7 9 1 1 0 6 , 9 6 ^ { * * }}$ & $192,06^{*}$ \\
\hline Coef. var (\%) & $\mathbf{2 0 , 0 3}$ & $\mathbf{8 , 2 7}$ & $\mathbf{8 , 1 1}$ & $\mathbf{5 , 2 5}$ & $\mathbf{2 6 , 2 3}$ & $\mathbf{4 5 , 6 4}$ \\
\hline
\end{tabular}

*,** e ns: significativo a 5 e $1 \%$ de probabilidade e não significativo pelo teste $\mathrm{F}$ da análise de variância; (1) No teste da VIB foi considerada a profundidade do solo de 0 a $20 \mathrm{~cm}$.

Fonte: Elaboração dos autores

O teste Tukey (Tabela 2) não detectou diferença significativa entre médias de VTP, macroporosidade (Ma) e microporosidade (Mi) nas profundidades de solo entre 0 e $10 \mathrm{~cm}$ e entre 10 e 20 cm. Considerando que a matéria orgânica do solo tem importância na estruturação dos solos, com influência na velocidade de infiltração de água (BRANDÃo et al., 2009), e que é preciso um tempo mínimo para sua incorporação a esse solo (SATO et al., 2012), a ausência da referida significância possivelmente, ocorreu pelo fato das alterações físicas do solo nos sistemas estudados de rotação das espécies vegetais necessitarem mais tempo para se diferenciar, o que dificultou a discussão dos resultados sobre a velocidade de infiltração básica (VIB) como indicador qualitativo do sistema poroso.

Tabela 2. Valores médios das características avaliadas: macroporosidade (Ma), microporosidade (Mi), volume total de poros (VTP), densidade do solo (Ds), resistência do solo à penetração (Rsp) e velocidade de infiltração básica nas profundidades de 0 a $10 \mathrm{~cm}$ e 10 a $20 \mathrm{~cm}$ observadas nas áreas cultivadas anteriormente ao milho com sorgo, feijoeiro, milheto e braquiária. Para velocidade de infiltração básica (VIB) obteve-se apenas um valor médio considerando-se a profundidade do solo de 0 a $20 \mathrm{~cm}$.

\begin{tabular}{|c|c|c|c|c|c|c|c|}
\hline Trat. & Prof. & $\begin{array}{c}\mathrm{Ma} \\
(\%)\end{array}$ & $\begin{array}{c}\text { Mi } \\
(\%) \\
\end{array}$ & $\begin{array}{l}\text { VTP } \\
(\%)\end{array}$ & $\begin{array}{c}\text { Ds } \\
\left(\mathrm{g} \mathrm{cm}^{-3}\right)\end{array}$ & $\begin{array}{c}\text { Rsp } \\
(\mathrm{kPa})\end{array}$ & $\begin{array}{c}\text { VIB } \\
\left(\mathrm{cm} \mathrm{hora}{ }^{-1}\right)\end{array}$ \\
\hline \multirow[t]{3}{*}{ Sorgo } & 0 a $10 \mathrm{~cm}$ & $13,16 A^{(1)}$ & $35,67 \mathrm{~A}$ & $48,82 \mathrm{~A}$ & 1,29 & $867,24 \mathrm{~A}$ & - \\
\hline & 10 a $20 \mathrm{~cm}$ & $15,63 a$ & $32,06 a$ & 47,69 & 1,33 & $1758,43 a$ & \\
\hline & Média & 14,40 & 33,86 & 48,26 & 1,31 & 1312,84 & 10,65 \\
\hline \multirow[t]{3}{*}{ Feijoeiro } & 0 a $10 \mathrm{~cm}$ & $16,47 \mathrm{~A}$ & $35,13 \mathrm{~A}$ & $51,60 A$ & 1,29 & $563,3 \mathrm{~B}$ & - \\
\hline & 10 a $20 \mathrm{~cm}$ & $13,42 a$ & $36,96 a$ & 50,38 & 1,37 & $1680,62 a$ & - \\
\hline & Média & 13,42 & 36,04 & 50,99 & 1,33 & 1121,96 & 14,14 \\
\hline \multirow{3}{*}{ Milheto } & 0 a $10 \mathrm{~cm}$ & $9,33 \mathrm{~A}$ & $34,46 \mathrm{~A}$ & $43,79 A$ & 1,36 & $514,84 \mathrm{~B}$ & \\
\hline & 10 a $20 \mathrm{~cm}$ & $14,12 a$ & $30,88 a$ & 45,00 & 1,32 & $1263,05 b$ & \\
\hline & Média & 14,12 & 32,67 & 44,39 & 1,34 & 888,95 & 26,55 \\
\hline \multirow{3}{*}{ Braquiária } & 0 a $10 \mathrm{~cm}$ & $7,07 \mathrm{~A}$ & $43,40 \mathrm{~A}$ & $50,46 \mathrm{~A}$ & 1,24 & $483,56 \mathrm{~B}$ & - \\
\hline & 10 a $20 \mathrm{~cm}$ & $8,48 a$ & $43,10 a$ & 51,58 & 1,24 & $1210,71 b$ & - \\
\hline & Média & 8,48 & 43,25 & 51,02 & 1,24 & 847,14 & 14,70 \\
\hline
\end{tabular}

(1) Médias nas colunas contendo letras iguais maiúsculas $(0-10 \mathrm{~cm})$ e minúsculas $(10-20 \mathrm{~cm})$ não diferem entre si pelo teste Tukey a $5 \%$ de probabilidade. Os valores de VIB estão de acordo com os limites sugeridos por North Central 206 Regional Comittee 40, citado por Rawls et al. (1996)

Fonte: Elaboração dos autores

A alteração da porosidade total nos sistemas de uso e manejo influenciando negativamente sobre a taxa de infiltração e infiltração acumulada foi verificada no trabalho de Anjos et al. (1994). Segundo Silva et al.(2000), a redução do volume total de poros dá-se pela redução principal da macroporosidade e aumento da microporosidade do solo. A associação direta da velocidade de infiltração básica de água no solo com sua macroporosidade foi relatada no estudo de Cadima et al. (1980), 
com a constatação da correlação linear positiva entre a condutividade hidráulica do solo saturado e a macroporosidade por Brandão et al. (2009).

No presente trabalho constatou-se correlação linear negativa (Tabela 3) entre VIB e VTP. Considerando que Mi correlacionou-se positivamente com VTP e Ma correlacionou-se negativamente com VTP possivelmente, o aumento do VTP nas condições experimentais deu-se pelo aumento da Mi, que dificultou a infiltração de água no solo, sendo a Ma mais atuante indiretamente sobre o aumento da VIB. Deve-se, ainda, considerar que a VIB foi maior na área onde se cultivou milheto anteriormente ao milho (Tabela 2), e que nesse sistema houve menor relação existente entre Mi e Ma.

Tabela 3. Coeficientes de correlação linear $(r)$ simples obtidas entre as médias das características macroporosidade, microporosidade, volume total de poros (VTP), densidade do solo (Ds) e resistência do solo a penetração (Rsp) provenientes dos valores obtidos nas profundidades do solo entre 0 a $10 \mathrm{~cm}$ e 10 a $20 \mathrm{~cm}$, além da velocidade de infiltração básica (VIB) e produtividade (Prod).

\begin{tabular}{ccccccc}
\hline Microp. & VTP & Ds & VIB & Rsp & Prod & \\
\hline$-0,98^{* *}$ & $-0,58 \mathrm{~ns}$ & $0,93^{* *}$ & $0,12 \mathrm{~ns}$ & $0,62 \mathrm{~ns}$ & $0,68 \mathrm{~ns}$ & Macrop. \\
& $0,73 \mathrm{~ns}$ & $-0,93^{* *}$ & $-0,28 \mathrm{~ns}$ & $-0,48 \mathrm{~ns}$ & $-0,62 \mathrm{~ns}$ & Microp. \\
& & $-0,57 \mathrm{~ns}$ & $-0,71 \mathrm{~ns}$ & $0,13 \mathrm{~ns}$ & $-0,15 \mathrm{~ns}$ & VTP \\
& & & $0,36 \mathrm{~ns}$ & $0,37 \mathrm{~ns}$ & $0,87^{* *}$ & Ds \\
& & & & $-0,70 \mathrm{~ns}$ & $0,24 \mathrm{~ns}$ & VIB \\
& & & & & $0,27 \mathrm{~ns}$ & Rsp \\
\hline
\end{tabular}

*,** e ns: significativo a 5 e $1 \%$ de probabilidade e não significativo pelo teste t.

Fonte: Elaboração dos autores

À associação da Ma com VIB pode-se acrescentar outros dois fatores importantes, sendo eles a continuidade e o formato dos poros (BRANDÃO et al., 2009). Suzuki e Alves (2005) atribuíram as maiores taxas de infiltração de água na área de mata à maior continuidade de poros desde a superfície, possibilitada pela possível estruturação do solo. Gonçalves e Moraes (2012), por meio de análise de imagens de seções finas ou blocos de solo a partir de amostras não-deformadas, constataram que a infiltração de água no solo foi influenciada pelos canais formados pela fauna e/ou apodrecimento de raízes com a criação de bioporos alongados — importantes na percolação de água no solo (PAGLIAI et al.,1983) - que representaram maior porção da porosidade nos sistemas agrícolas conservacionistas.

Sistemas agrícolas conservacionistas baseiam-se principalmente na qualidade e quantidade da matéria orgânica remanescente em superfície e/ou incorporada ao solo como preceito para estruturação e estabilização dos seus agregados. 0 aporte quantitativo e qualitativo dos materiais orgânicos nas áreas agrícolas favorece atividade biológica em conjunto com a conservação do solo.

A maior Ma observada no local cultivado com milheto anteriormente ao milho, a qual se pretende aqui estabelecer sua relação com a VIB, foi atribuída a maior quantidade de massa seca remanescente na superfície do solo ao longo do período experimental (Figura 1), o que implicou, possivelmente, maior estruturação do solo por questões que vão desde a mineralização do material orgânico, perpassando pela retenção de umidade até o estímulo da atividade biológica no desenvolvimento de bioporos alongados e de cavidades e canais biológicos. Ainda, sabe-se que uma melhor cobertura vegetal previne o "selamento" do solo (BARCELOS et al., 1999), consequência da sua desestruturação seguida de obstrução dos espaços vazios por particulados coloidais. 


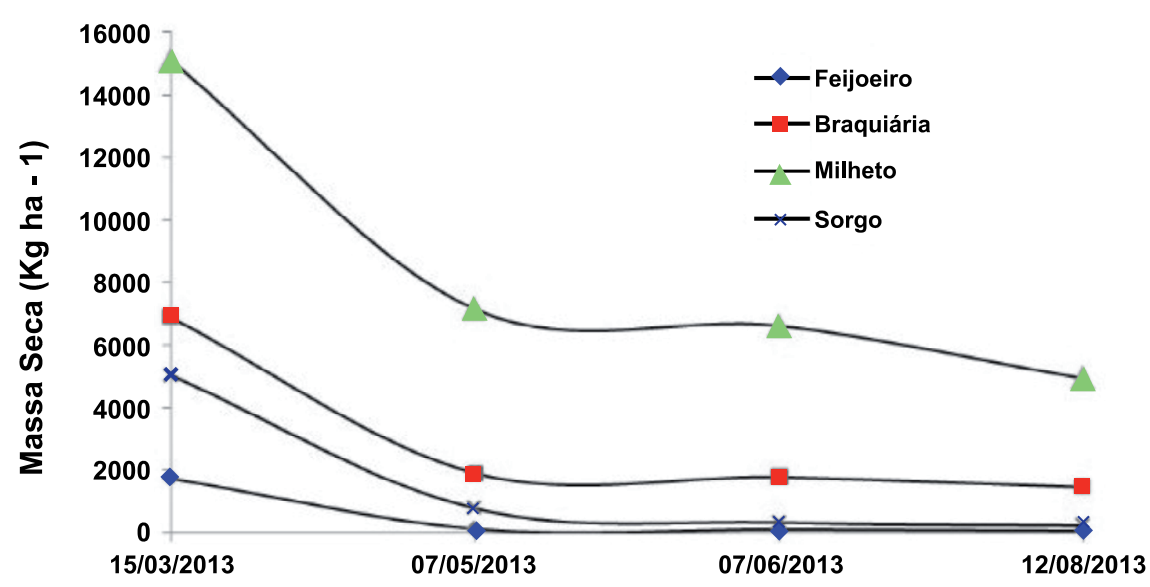

Figura 1. Perda de massa das espécies vegetais cultivadas anterior ao milho. Confresa-MT, Brasil. Fonte: Elaboração dos autores

Gramíneas têm sido componente importante do sistema de produção agrícola, com destaque para milheto por ter resistência ao deficit hídrico, elevada produção de biomassa e menor custo das sementes (BRAZ et al., 2004), sendo capaz de melhorar os atributos químicos e físicos do solo com consequências positivas sobre a redução da erosão e do escoamento superficial, aumento da infiltração e retenção de água e ciclagem de nutrientes no perfil (DEBARBA; AMADO, 1997; BAYER; MIELNICZUK, 1997; FRANCHINI et al., 1999; AMADO et al., 2000).

A tentativa de associação da VIB com Ma também pode ser realizada observando-se a resistência do solo a penetração (Rsp). Foi observada correlação linear positiva (Tabela 3) entre Rsp e $\mathrm{Ma}$, diferente do esperado, que contempla redução da macroporosidade do solo com aumento da sua resistência à penetração (CARDOSO et al., 1992; TORMENA et al., 2002). No entanto, nota-se que o aumento da VIB está correlacionado negativamente com o VTP, que por sua vez tende a reduzir com aumento da Ma (ver coeficiente de correlação no Tabela 3). Com isso, caso haja aumento da Ma, o VTP tenderá a ser reduzido, com aumento dos valores de Rsp.

Cabe ressaltar sobre a Rsp, uma vez que para tal característica constatou-se diferença significativa pelo teste Tukey (Tabela 2), os menores valores nas áreas cultivadas com milheto e braquiária antecedente ao cultivo do milho. Observando os postulados de Gomes e Peña (1996) e Imhoff et al. (2000), que a resistência do solo à penetração constitui um parâmetro físico altamente influenciado pela umidade, pode-se supor que a água do solo em maiores teores nas referidas áreas, considerando a maior quantidade de resíduos vegetais remanescentes ao longo do período experimental (Figura 1), atuou como "lubrificante" entre partículas e a haste do penetrógrafo no solo (GUERRA et al., 2000). Complementando, o aumento do teor de água, decresce a atuação das forças de coesão entre as partículas do solo e o atrito interno, provocando, então, a diminuição da RP (CUNHA et al., 2002).

Embora não havendo diferença significativa pelo teste Tukey (Tabela 2), foi para o cultivo de feijoeiro anterior ao milho que se constatou maior produtividade de grãos de milho (Figura 2).

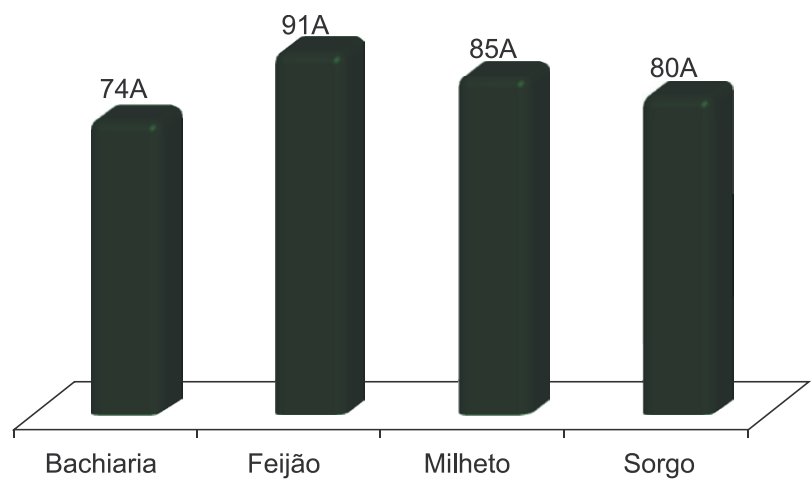

Figura 2. Produtividade de grãos de milho em sacas de $60 \mathrm{~kg}$ cultivado sobre resíduos vegetais de braquiária, feijoeiro, milheto e sorgo. Confresa-MT, julho de 2013

Fonte: Elaboração dos autores 
No presente estudo, obteve-se uma condição de porosidade do solo nos sistemas agrícolas avaliados próxima ao ideal segundo Kiehl (1979), a onde a porosidade total deve ser de 50\%, sendo um terço $(16,50 \%)$ de macroporos e dois terços $(33,33 \%)$ de microporos, com exceção da área cultivada com braquiária e posteriormente milho.

Embora aqui se deva relacionar a produtividade de grãos de milho com a porosidade do solo, sabe-se que a produtividade das espécies vegetais em sistemas de rotação ou sucessão de culturas depende sobretudo da taxa de mineralização e das quantias mineralizadas dos nutrientes principais.

A mineralização dos materiais vegetais no solo pode ser rápida e intensa (ROSOLEM et al., 2003), ou lenta e gradual, conforme a interação entre os fatores climáticos, principalmente precipitação pluvial e temperatura, atividade macro e microbiológica do solo e qualidade e quantidade do resíduo vegetal (ALCÂNTARA et al., 2000; OLIVEIRA et al., 2002).

Espécies com maior quantidade de nitrogênio na composição têm maior taxa de mineralização do elemento (KRIFT; BERENDSE, 2001). Além disso, segundo os referidos autores, a nitrificação é maior e mais rápida com disponibilização de nitrato, ao passo que resíduos com menor quantidade de $\mathrm{N}$ em sua composição foram mais lentos na ciclagem do nitrogênio no solo.

Com o desenvolvimento do milho, no presente estudo, há redução nas quantidades de nitrogênio inorgânico no solo, como observado por Siqueira Neto et al., (2010) em decorrência da absorção desse nutriente. Portanto, é possível, que a absorção dos nutrientes - principalmente nitrogênio - pela planta de milho cultivada posterior ao feijoeiro (relação $\mathrm{C} / \mathrm{N}$ mais baixa em relação a braquiária, miIheto e sorgo) tenha sido maior, pelos benefícios da maior mineralização dos nutrientes provenientes da decomposição mais rápida dos resíduos do feijoeiro e/ou dos nutrientes contidos nos fertilizantes adicionados. Deve-se ressaltar, ainda, a mobilização dos nutrientes - principalmente do nitrogênio - provenientes das fontes de fertilizantes em áreas de implantação de sistemas conservacionistas.

\section{Conclusões}

Nas condições experimentais avaliadas foi possível utilizar a velocidade de infiltração básica de água no solo (VIB) como indicador da qualidade do seu sistema poroso, embora tenha sido necessário realizar associações indiretas com as características avaliadas. Dessa forma, constatou-se tendência do aumento da VIB com aumento da macroporosidade.

\section{Agradecimento}

Ao Conselho Nacional de Desenvolvimento Científico e Tecnológico (CNPq) que financiou o presente trabalho por meio da Chamada Pública CNPq/VALE S.A. n. ${ }^{\circ}$ 05/2012 - Forma-Engenharia.

\section{Basic infiltration velocity of water as an indicator of the po- rous quality of soil Abstract}

This study examined whether the infiltration rate of water (VIB) can be an indicator of the quality of the porous system of soils under different plant species. Was conducted in the municipality of Confresa (MT) Alfissol in an Ultisol sandy texture tillaged. The experimental design was a randomized block with four treatments for crops Brachiaria ruziziensis, Pennisetum americanum, Phaseolus vulgaris L. and Sorghum bicolor L. Moench in four replicates totaling 16 plots. The idea of the cultivation of those plant species has been promoting natural changes in the diameter of the pores of the soil through their root systems and mineralization of waste, enabling the study of the infiltration rate of water into the soil as an indicator of the quality of the caliber of pores. From 90 days after sowing of maize evaluated the soil bulk density, macroporosity (Ma), micropores (Mi), total porosity (VTP), soil penetration resistance (Rsp) and VIB. The soil depths considered were 0,00 to 0,10m me from 
0,10 to $0,20 \mathrm{~m}$. Numerical data were analyzed using ANOVA and significance of " $\mathrm{F}$ " at $5 \%$ probability. Significant features had their means compared by Tukey method. Among the features cited were obtained correlation coefficients of simple linear Pearson. In our experimental conditions it was possible to use the VIB as an indicator of the quality of its pore system, although it was necessary to conduct indirect associations with the traits. Thus, we found a trend of increased VIB with increased macroporosity.

Key words: Porosity. Management. Vegetable residues.

\section{Referências Bibliográficas}

AlCÂNTARA, F. A.; FURTINI NetO, A. E.; PAUlA, M. B. De; MESqUitA, H. A. de; MUNIZ, J. A. Adubação verde na recuperação da fertilidade de um Latossolo Vermelho-Escuro degradado. Pesquisa Agropecuária Brasileira, v. 35, n. 2, p. 277-288, 2000.

ALVES, M. C. Infiltração de água em um Podzólico Vermelho-Escuro sob dois métodos de preparo, usando chuva simulada com duas intensidades. 1986. 115 f. Dissertação. (Mestrado em Agronomia). Universidade Federal do Rio Grande do Sul, Porto Alegre, [1986].

ALVES, M. C.; CABEDA, M. S. V. Infiltração de água em um Podzólico Vermelho-Escuro sob dois métodos de preparo, usando chuva simulada com duas intensidades. Revista Brasileira de Ciência do Solo, v. 23, n. 4, p. 753-761, 1999.

AMADO, T. J. C.; MIELNICZUK, J.; FERNANDES, S. B. V. Leguminosas e adubação mineral como fontes de nitrogênio para o milho em sistemas de preparo do solo. Revista Brasileira de Ciência do Solo, v. 24, n. 1, p. 179-189, 2000.

ANJOS, J. T.; UBERTI, A. A. A.; VIZZOTTO, V. J.; LEITE, G. B.; KRIEGER, M. Propriedades físicas em solos sob diferentes sistemas de uso e manejo. Revista Brasileira de Ciência do Solo, v. 18, n. 1, p. 139-145, 1994.

BARCELOS, A. A.; CASSOL. E. A.; DENARDIN, J. E. Infiltração de água em um latossolo vermelhoescuro sob condições de chuva intensa em diferentes sistemas de manejo. Revista Brasileira de Ciência do Solo, v. 23, n. 1, p. 35-43, 1999.

BAYER, C.; MIELNICZUK, J. Características químicas do solo afetadas por métodos de preparo e sistemas de cultura. Revista Brasileira de Ciência do Solo, v. 21, n. 1, p.105-112, 1997.

BERTOL, I.; ALBUQUERQUE, J. S.; LEITE, D.; AMARAL, A. \& ZORDAN JUNI-OR, W.A. Propriedades físicas do solo sob preparo convencional e semeadura direta em rotação e sucessão de culturas comparadas às do campo nativo. Revista Brasileira de Ciência do Solo, v. 28, n. 2, p. 337-345, 2004.

BRANDÃO, V. S.; PRUSKI, F. P.; SILVA, D. D. Infiltração da água no solo. 3. ed. Viçosa: UFV, 2009.

BRAZ, A. J. B. P.; SILVEIRA, P. M. Da; KLIEMANN, H. J.; ZIMMERMANN, F. J. P. Acumulação de nutrientes em folhas de milheto e dos capins braquiária e mombaça. Pesquisa Agropecuária Tropical, v. 34, n. 2, p. 83-87, 2004.

CADIMA, A; LIBARDI, P.L.; REICHARDT, K. Variabilidade espacial da condutividade hidráulica em um Latossolo Vermelho - Amarelo textura média, no campo. Revista Brasileira de Ciência do Solo, v. 4 , n. 2 , p. 63-66, 1980.

CARDOSO, E. J. B. N.; TSAI, S. M.; NEVES, M. C. P. Microbiologia do Solo. Campinas: Sociedade Brasileira de Ciência do Solo, 1992. 
CARPENEDO, V.; MIELNICZUK, J. Estado de agregação e qualidade dos agregados de latossolos roxos, submetidos a diferentes sistemas de manejo. Revista Brasileira de Ciência do Solo, v. 14, n. 1, p. 99-105, 1990.

CASSOL, E. A. Erosão do solo: influência do uso agrícola, do manejo e preparo do solo. 2. ed. Porto Alegre, IPRNR-Ataliba Paz, 1986.

CABEDA, M. S. V. Degradação física e erosão do solo. In: SIMPÓSIO DE MANEJO DO SOLO E PLANTIO DIRETO NO SUL DO BRASIL, 1.,1984, Passo Fundo. Anais... Passo Fundo PIUCS e UPF - Faculdade de Agronomia,1984. p. 28-33.

CUNHA, J. P.A. R. da; VIEIRA, L. B.; MAGALHÃES, A. C. Resistência mecânica do solo à penetração sob diferentes densidades e teores de água. Engenharia na Agricultura, Viçosa, v. 10, n. 1-4, p. 1-7, 2002.

DEBARBA, L.; AMADO, T. J. C. Desenvolvimento de sistemas de produção de milho no Sul do Brasil com características de sustentabilidade. Revista Brasileira de Ciência do Solo, v. 21, n. 3, p. 473480, 1997.

DORAN, J. W.; PARKIN, T. B. Defining and assessing soil quality. In: DORAN, J. W.; COLEMAN, D. C.; BEZDICEK, D. F.; STEWART, B. A., (Orgs.) Defining soil quality for a sustainable environment. Madison, ASA, CCSA, SSSA, 1994. p. 3-21.

DUNN, G. H.; PHILLIPS, R. E. Macroporosity of a well-drained soil under notill and conventional tillage. Soil Science Society American Journal, v. 55, n. 2, p. 817-823, 1991.

EMPRESA BRASILEIRA DE PESQUISA AGROPECUÁRIA (EMBRAPA). Manual de métodos de análises de solo. 2. ed. Rio de Janeiro: EMBRAPA-CNPS, 2011.

. Centro Nacional de Pesquisa de Solos. Sistema brasileiro de classificação de solos. 2. ed. Rio de Janeiro, 2006.

FRANCHINI, J. C.; MIYAZAWA, M.; PAVAN, M. A.; MALAVOLTA, E. Dinâmica de íons em solo ácido lixiviado com extratos de resíduos de adubos verdes e soluções puras de ácidos orgânicos. Pesquisa Agropecuária Brasileira, v. 34, n. 12, p. 2267-2276, 1999.

GUERRA, S. P. S.; LANÇAS, K. P.; MAZETTO, F. R. Utilização do G.P.S. e do penetrômetro hidráulicoeletrônico para localização de pontos e avaliação da compactação do solo. In: REUNIÃO CIENTÍFICA EM CIÊNCIAS AGRÁRIASS DO LAGEADO. 20030, Botucatu. Resumos... Botucatu: Universidade Estadual Paulista, 2000. p. 85.

GOMES, A. de S.; PEÑA, Y. A. Caracterização da compactação através do uso do penetrômetro. Lavoura Arrozeira, Porto Alegre, v. 49, n. 1, p. 18-20, 1996.

IMHOFF, S.; SILVA. A. P.; TORMENA, C. A. Aplicações da curva de resistência no controle de qualidade física de um solo sob pastagem. Pesquisa Agropecuária Brasileira. Brasilia (DF), v. 35, n. 7, p. 1493-1500, 2000.

KIEHL, E. J. Manual de edafologia. São Paulo: Agronômica Ceres, 1979.

KRIFT, T. A. J. Van Der.; BERENDSE, F. The effect of plant species on soil nitrogen mineralization. Journal of Ecology, v. 89, n. 4, p. 555-561, 2001.

LOVATO, T.; MIELNICZUK, J.; BAYER, C. \& VEZZANI, C. Adição de carbono e nitrogênio e sua relação com os estoques no solo e com o rendimento do milho em sistemas de manejo. Revista Brasileira de Ciência do Solo, v. 28, n. 1, p. 175-187, 2004. 
SIQUEIRA NETO, M.; PICCOLO, M. De CÁSSIA.; FILHO, S. De PAIVA V.; FEI-GL, B. J. CERRI, C. C. Mineralização e desnitrificação do nitrogênio no solo sob sistema plantio direto. Bragantia, v. 69, n. 4, p. 923-936, 2010.

OLIVEIRA, T. K.; CARVALHO, G. J.; MORAES, R. N. S. Plantas de cobertura e seus efeitos sobre o feijoeiro em plantio direto. Pesquisa Agropecuária Brasileira, v. 37, n. 8, p. 1079-1087, 2002.

OLIVEIRA, G. C.; DIAS JUNIOR, M. S.; RESCK, D. V. S., CURI, N. Caracterização química e físicohídrica de um Latossolo Vermelho após vinte anos de manejo e cultivo do solo. Revista Brasileira de Ciência do Solo, v. 28, n. 2, p. 327-336, 2004.

PAGLIAI, M.; LA MARCA, M.; LUCAMONTE, G. Micromorphometric and micro-morphological investigations of a clay loam soil in viticulture under zero and conventional tillage. Journal of Soil Science, v. 34, n. 2, p. 391-403, 1983.

PANACHUKI, E.; ALVES SOBRINHO, T.; VITORINO, A. C. T.; CARVALHO, D. F.; URCHEI, M. A. Avaliação da infiltração de água no solo, em sistema de integração agricultura-pecuária, com uso de infiltrômetro de aspersão portátil. Acta Scientiarum. Agronomy, v. 28, n. 1, p.129-137, 2006.

RAWLS, W. L.; DAVID, G. VAM MULLEN, J. A.; WARD, T. J. Infiltration. In: ASCE. Hidrology Handbook. 2. ed. New York, 1996. p. 75-124.

ROSOLEM, C. A.; CALONEGO, J. C.; FOLONI, J. S. S. Lixiviação de potássio da palha de coberturas de solo em função da quantidade de chuva recebida. Revista Brasileira de Ciência do Solo, v. 27, n. 2, p. 355-362, 2003.

SATO, J. H.; FIGUEIREDO, C. C. De.; LEÃO, T. P.; RAMOS, M. L. G.; KATO, E. Matéria orgânica e infiltração da água em solo sob consórcio milho e forrageiras. Revista Brasileira de Engenharia Agrícola e Ambiental, v. 16, n. 2, p. 189-193, 2012.

SILVA, L. C.; KATO, E. Avaliação de modelos para a previsão da infiltração de água em solos sob cerrado. Pesquisa Agropecuária Brasileira, v. 33, n. 7, p. 1149-1158, 1998.

SILVA, V. R.; REINERT, D. J.; REICHERT, J. M. Densidade do solo, atributos químicos e sistema radicular do milho afetados pelo pastejo e manejo do solo. Revista Brasileira de Ciência do Solo, v. 24, n. 1, p. 191-199, 2000.

SOBRINHO, T. A.; VITORINO, A. C. T.; SOUZA, L. C. F. De.; GONÇALVES, M. C.; CARVALHO, D. F. De. Infiltração de água no solo em sistemas de plantio direto e convencional. Revista Brasileira de Engenharia Agrícola e Ambiental, v. 07, n. 2, p. 191-196, 2003.

SUZUKI, L. G. A. S.; ALVES, M. C. Propriedades químicas de um solo em recuperação tratado com diferentes fontes de matéria orgânica. In: SIMPÓSIO NACIONAL DE RECUPERAÇÃO DE ÁREAS DEGRADADAS, 6.; CONGRESSO LATINO-AMERICANO SOBRE RECUPERAÇÃO DE ÁREAS DEGRADADAS. 2005. Curitiba. Anais... UFPR/Fundação de Pesquisas Florestais do Paraná, Sociedade Brasileira de Recuperação de Áreas Degradadas. Curitiba, 2005. p. 1-13.

TORMENA, C. A.; BARBOSA, M. C.; COSTA, A. C. S. Da.; GONÇALVES, C. A. Densidade, porosidade e resistência à penetração em Latossolo cultivado sob diferentes sistemas de preparo do solo. Scientia Agricola, v. 59, n. 4, p. 795-801, 2002.

Histórico Editorial

Recebido em: 05/09/2013

Aceito em: 10/02/2014 